\title{
Color fraction as a useful method of imaging synovium vascularization in patients with high activity of rheumatoid arthritis
}

\author{
Michat Jakubaszek ${ }^{1}$, Mateusz Płaza ${ }^{2}$, Brygida Kwiatkowska ${ }^{1}$ \\ ${ }^{1}$ Early Arthritis Clinic, National Institute of Geriatric, Rheumatology and Rehabilitation, Warsaw, Poland \\ ${ }^{2}$ Department of Radiology, National Institute of Geriatric, Rheumatology and Rehabilitation, Warsaw, Poland
}

\begin{abstract}
Rheumatoid arthritis (RA) is an autoimmune disease with joint inflammation and destruction as the main features that appears with prevalence of 1 to $2 \%$ of the general population. Women are three times more likely to suffer from RA than men. Rheumatoid arthritis occurs at any age but commonly over 40-50 years old. In the course of RA each joint may be involved but most frequently the proximal interphalangeal and metacarpophalangeal joints of the hands, wrists, and also small joints of the feet are affected.

Symmetrical joint swelling with overgrowth of synovium and hypervascularization confirmed in power Doppler ultrasound imaging are very characteristic for RA. Quantification of vascularization with the color fraction index may be a useful tool to monitor disease activity and in evaluation of inflammation in scientific research.

This article aims to present this imaging diagnostic method based on the literature.
\end{abstract}

Key words: color fraction, synovium inflammation, rheumatoid arthritis, disease activity.

\section{Introduction}

Ultrasound imaging (US) is a common method used in the diagnosis of arthritis in rheumatic diseases. This method is non-invasive, accessible and reproducible, does not cause discomfort to patients and, what is also important, inexpensive compared to e.g. magnetic resonance imaging (MRI). Ultrasonography is not included in diagnostic criteria for rheumatoid arthritis (RA) but is very helpful as a supplementation of physical examination and is highly sensitive in detecting effusion and synovial hypertrophy. Importantly, in healthy joints synovium is not visible in US examination but ultrasonographic assessment of synovium is helpful especially in patients with early arthritis when physical examination does not bring a clear diagnosis of inflammation in painful joints. Using US we can image even slight synovium hypertrophy and using the power Doppler (PDUS) method may confirm synovial hypervascularity. Using a high-frequency linear probes, sensitive Doppler and harmonic imaging, US has the potential to show even small synovium hypertrophy.

Classic radiography (CR) is not as sensitive as US in detecting early stage inflammatory bone destruction, which means erosions [1]. In the course of RA, the synovial tissue overgrows and forms numerous villous folds that bulge into the joint cavity, and the number of type A synovial cells, macrophage-like synovial cells, and type B synovial cells, similar to fibroblasts, increases. Mononuclear cells, including $T$ and $B$ cells, macrophages and plasma cells move into the place of inflammation, which is supported by hypervascularization. These cells interact among themselves and produce and stimulate production of proinflammatory cytokines. Cytokine activity leads to cartilage destruction and the formation of bone erosions [2].

Address of correspondence:

Michał Jakubaszek, Early Arthritis Clinic, National Institute of Geriatric, Rheumatology and Rehabilitation, 1 Spartańska St., 02-637 Warsaw, Poland, e-mail: michal.jakubaszek@wp.pl

Submitted: 29.01.2020; Accepted: 20.02.2020 


\section{Color fraction as part of ultrasonography method}

Power Doppler ultrasonography is a very good tool to investigate local inflammation. Doppler signals are interpreted as the number of red blood cells captured by the transducer and the speed at which they pass, and thus by measuring the colored pixels we learn about the relative amount of moving blood in the area that is being examined $[3,4]$. Color pixels are usually rarely seen in healthy joints, and it is certain that when they appear in a synovial membrane it is a sign of an increase in the relative amount of moving blood. Recently use of machines with very sensitive PDUS improves detection of signs of structural damage and joint inflammation even in small joints of the hands and feet [5]. The number of color pixels visualized by PDUS brings the knowledge about already existing vascularization but does not indicate the number of vessels [6]. This method allows detection of the inflammatory process by counting the color pixels, which are interpreted as a sign of hyperemia [7]. In clinical practice not only color Doppler but also spectral Doppler as well proved to be an objective and easy method to estimate the degree of synovial inflammation [8].

The degree of hypertrophy and synovitis can be assessed on a quantitative, semi-quantitative or qualitative scale. The semi-quantitative scoring system is the most frequently applied method, in which a four-step scale is used to measure the intensity of the synovial blood flow. Szkudlarek et al. [9] proposed the gray-scale ultrasound score (0-3); grade 0 denotes no inflammatory changes, and grades 1 to 3 denote respectively mild, moderate and marked synovial hypertrophy. According to the Doppler scale (0-3), grade 0 means there no signs of synovial flow, grade 1 only isolated signals within hypertrophied synovium, grade 2 means that vessels that

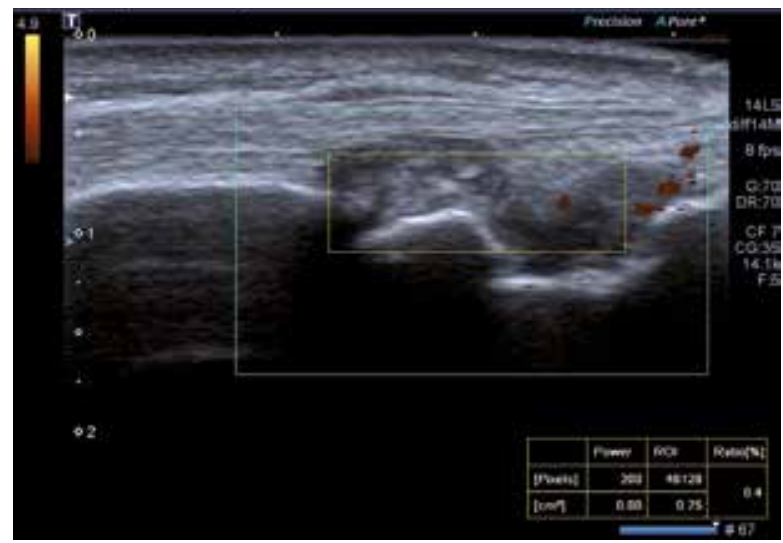

Fig. 1. Low degree of vascularization in the wrist measured with CF. occupy less than $50 \%$ of the hypertrophied synovial area, and finally grade 3 means that more than $50 \%$ of the examined area is affected [10, 11].

Computer-assisted measurement of color pixels uses a qualitative scale where a region of interest (ROI) is an exact region of interest pixels. In this area the examiner measures the color pixels and defines them this is the scale proposed by Ellegaard et al. [12]. Using this method we find a correlation between ROI and the intraarticular region inside the joint capsule.

In clinical trials the color fraction (CF) index was found to correlate with the clinical indicators of inflammation: number of swollen joints, erythrocyte sedimentation rate, C-reactive protein level and Disease Activity Score 28 (DAS28), clinical disease activity index (CDAI), simple disease activity index (SDAI). Using the CF method we can also verify effects of therapies. If the treatment of RA is effective it leads to a reduction in color signals. There is a correlation between scores and the longitudinal assessment of the clinical activity in RA [13-16]. It is very important that sometimes despite achieving clinical remission the persisting subclinical inflammatory activity leads to disease progression. Power Doppler ultrasound and CF were analyzed as a method of disease diagnosis and treatment monitoring; scoring system and quantitative evaluation seemed to be especially valuable for comparative assessment of treatment efficacy [14-18].

Andersen et al. [19] evaluated 81 synovial sites from wrist and finger joints from 29 RA patients by ultrasound color Doppler CF and subsequently biopsied by needle arthroscopy. In this examination CF results were associated with the overall synovitis score. The authors found an association of CF with measures of density of all immunohistochemical staining, but they noted that synovial pathology was also seen in biopsies taken from sites in which CF were negative.

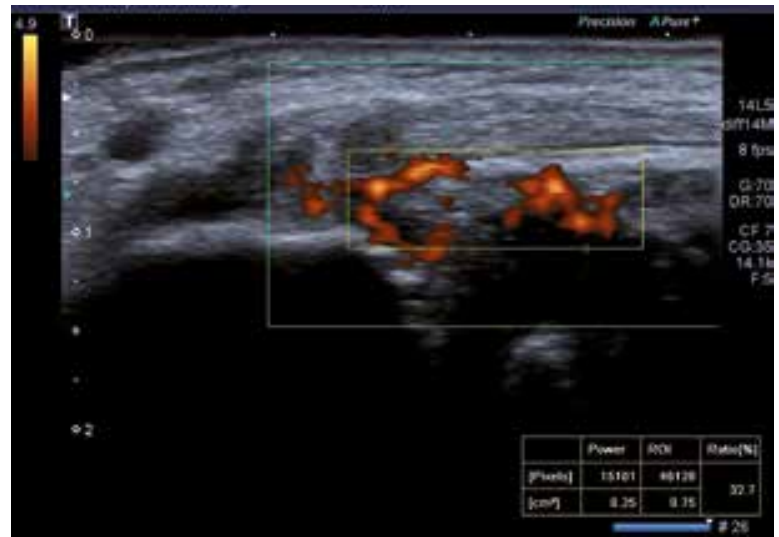

Fig. 2. High degree of vascularization in the wrist measured with CF. 
Table I. Ultrasonography (US) versus magnetic resonance imaging (MRI) in joint evaluation in rheumatoid arthritis $[24,25]$

\begin{tabular}{|c|c|}
\hline US & MRI \\
\hline Quick & Time consuming \\
\hline Inexpensive & Rather expensive \\
\hline Does not use any radiation & Using magnetic field \\
\hline $\begin{array}{l}\text { May be available for real time use and with dynamic } \\
\text { assessment (during movement) }\end{array}$ & Without dynamic assessment (during joint motion) \\
\hline $\begin{array}{l}\text { Well suited when multiple joint sites need to be } \\
\text { examined }\end{array}$ & More accurately evaluates specific joints or area \\
\hline $\begin{array}{l}\text { More accurate for examination of superficial or not } \\
\text { very deep structures }\end{array}$ & $\begin{array}{l}\text { Allows one to find bone marrow edema (BME) at very early stage } \\
\text { of inflammation, but }\end{array}$ \\
\hline $\begin{array}{l}\text { Color fraction method may be used for quantitative } \\
\text { vascularization assessment }\end{array}$ & $\begin{array}{l}\text { May be too sensitive and unspecific (may be present in: } \\
\text { osteomyelitis, osteoarthritis, intraosseous fracture, stress fracture, } \\
\text { osteoporosis, sickle cell crisis) }\end{array}$ \\
\hline $\begin{array}{l}\text { Semi-quantitative and quantitative measurements } \\
\text { of inflammation without using contrast agents may } \\
\text { be analyzed }\end{array}$ & $\begin{array}{l}\text { Contrast injection increases sensitivity for synovitis detection } \\
\text { In routine MRI scans could not visualize vascularization of synovium, } \\
\text { but }\end{array}$ \\
\hline $\begin{array}{l}\text { Patients with claustrophobia and metal foreign } \\
\text { objects (e.g. some types of prosthesis) may be } \\
\text { examined }\end{array}$ & $\begin{array}{l}\text { Dynamic contrast-enhanced magnetic resonance imaging (MRI) } \\
\text { increases the possibility of inflammation detection or drug injection } \\
\text { efficacy (e.g. glucocorticosteroids) }\end{array}$ \\
\hline May be used as a tool for guide for joint injections & Semi-quantitative and quantitative measurements of inflammation \\
\hline \multirow{3}{*}{$\begin{array}{l}\text { The accuracy and pertinence of the description } \\
\text { depend on the quality of the ultrasound machine/ } \\
\text { head and the experience of the examiner but have } \\
\text { good repeatability (experienced examiner) }\end{array}$} & Predictive value of MRI pathology for radiographic progression \\
\hline & Possible to examine deep structures \\
\hline & $\begin{array}{l}\text { Is better to evaluate structural damage to cartilage, bone or other } \\
\text { structures inside and around a joint }\end{array}$ \\
\hline $\begin{array}{l}\text { Real-time image, even with the possibility of taking } \\
\text { pictures, does not allow independent evaluation }\end{array}$ & $\begin{array}{l}\text { MRI scans are saved on CD and may be seen/consulted by } \\
\text { independent examiners }\end{array}$ \\
\hline
\end{tabular}

In Figures 1 and 2 different stages of synovial vascularization degree using CF are presented.

Schmidt et al. [20] stated that an update is needed in grading of ultrasound Doppler signals in synovitis. They showed that estimation of the CF is not so perfect and using computerized determination of the CF was more objective. The researchers examined 41 RA patients with mean disease duration of 11 years and mean DAS28 5.5 and showed that color signals were found in 192 of 984 joint regions. Forty-two, 139 and 11 regions were allocated to the semi-quantitative grades 1, 2 and 3 with electronically calculated color fractions of $3.9 \%, 12.6 \%$ and $29.7 \%$, respectively. The mean measured fractions were higher than the mean estimated color fractions. The authors found an even distribution of the scores for estimated color fractions of $>0-10 \%$ for grade $1,>10-25 \%$ for grade 2 and $>25 \%$ for grade 3 and for measured color fractions of $>0-6 \%$ for grade $1,>6-12 \%$ for grade 2 and $>12 \%$ for grade 3 and they suggested that more evenly distributed quantitative scores should replace the semi-quantitative grading system and that might better reflect the treatment response.

Terslev et al. [21] presented an evaluation of using ultrasound, including quantitative Doppler analysis of synovial vascularization in patients with RA who had intra-articular injections with glucocorticosteroids before and after treatment. The authors reported that one month after the injection with glucocorticosteroids, there was observed in as many as 41 out of 51 RA patients a decrease in the fraction of color pixels, and both the spectral Doppler resistive index (RI) values and fraction of color pixels corresponded to the subjective effect of the treatment and with the clinical evaluation.

Though color fraction is a quantitative scoring system (QS) and is better for evaluation of synovitis, in another study Terslev et al. [22] showed comparable scoring and semi-quantitative system (SQS). They performed headto-head comparison of SQS and QS ultrasound scoring systems for rheumatoid arthritis: agreement, reliability and methodology validity. In this study 46 RA patients who had evaluation of disease activity by DAS28 using 
CRP as a laboratory marker of inflammation and PDUS assessment were investigated. The examiners used the central position of the wrist and found high reliability and good agreement of both scoring systems when applied to the same patient cohort, and the study showed that these different scoring systems appear to be highly correlated.

Also Terslev at al. [23] examined hand and finger joints of 27 healthy volunteers with no symptoms of injury or joint inflammation, without previous history of trauma or arthritis. This study showed the presence of Doppler signals in $11 \%$ of examined subjects. It proves that when using new equipment with very sensitive Doppler settings we have to be very careful about interpretation of synovial vascularity.

However, US has a role in doubtful cases especially for patients with undifferentiated arthritis (UA). Using the joint effusion index (JEI), synovial hypertrophy index (GSI) and power Doppler index (PDI) including 8 or 12 or 52 joints it is possible to predict occurrence of RA or remission of inflammation. The GSI assessment has especially prognostic value for UA patients [24].

There is also the possibility of using other diagnostic methods such as MRI in the diagnosis of inflammatory changes in the course of early RA and other types of arthritis. It is known that the inflammatory process does not only involve the synovium but also takes place within the bone and subchondral bone marrow and articular fat, which can be shown with MRI as a bone marrow edema (BME) [25]. MRI is a reference method that also, like ultrasound, is helpful in early diagnosis of RA, follow-up, treatment and post-inflammatory joint damage. MRI allows a more global approach to small and large joints and the spine and is more sensitive and more specific than ultrasound $[26,27]$. Using the dynamic contrast-enhanced MRI (DCE-MRI) method we can obtain qualitative, semi-quantitative and quantitative measurements in dynamic active inflammation [28].

An advantage of US is that this is a quick and inexpensive method and can detect synovitis, tenosynovitis, tendonitis and bursitis. However, US depends on the quality of the US machine and is an operator-dependent method but allows dynamic examination and shows inflammatory changes to detect vascularization. Ultrasound is superior to MRI in the case of patients with claustrophobia or other contraindications for MRI. In MRI assessment there may also be overinterpretation in the case of significant overload of bone structures causing bone marrow edema. This method also does not allow the assessment of synovial vascularization. Both methods seems to have advantages and disadvantages, and which tool will be used depends on the clinical out- put required. In Table I the advantages and disadvantages of US vS MRI are presented.

During the development of medical technologies, another imaging method appeared to be useful for assessing inflammation and bone destruction in the course of RA; this is dual-energy CT (DECT). There is agreement between DECT and MRI for detection of BME [29]. The superiority of DECT is a lower cost and higher accessibility than MRI, but it is not available to all centers, so MRI is still performed in doubtful cases and for research purposes. However, none of these modern techniques will replace such an available and highly reproducible method as US.

Nevertheless, lately researchers have been discussing whether US is actually necessary to monitor disease activity of RA and to confirm disease remission. In the ARCTIC trial 10 rheumatology departments and one specialized center in Norway, from 2010 to 2015 conducted a randomized controlled study including 238 patients with RA [30].

All participants were naïve for disease-modifying anti-rheumatic drugs (DMARDs) at the beginning and during the trial had the same drug escalation strategy and were treated with the same DMARDs over two years. There were two arms of this trial. The conventional tight control strategy targeting clinical remission included 116 patients, and 122 patients were randomized to an ultrasound tight control strategy targeting clinical and imaging remission. This research proved that systematic US assessment is not necessary in the follow-up in early RA when the patients are properly treated according to current recommendations.

The authors suggested that further randomized trials are necessary to accept or reject wider application of medical technology. However, the research methodology assumed correct therapeutic management and confirmed diagnosis, and did not refer to doubtful cases and testing of new therapies, and it is in such cases that the US method together with a quantitative assessment in color fraction may be useful.

Also the TaSER [31] study comparing the US and DAS28 remission evaluation strategy during RA treatment focused on US usefulness in remission detection and evaluation of disease activity during RA treatment. This study showed that US results had an effect on treatment intensification but were not associated with a better clinical effect or, in imaging studies, treatment being conducted.

\section{Conclusions}

Power Doppler complemented by the CF method may be useful in the diagnosis of early RA and in mon- 
itoring of treatment in severe and difficult cases, and seems to useful as a method for assessment of prognosis for patients with UA. However, research from recent years showed sometimes conflicting and different data in this topic. This method may be used for confirmation of total clinical remission of arthritis, especially in clinical research.

However, it should be noted that this method has some limitations:

- high sensitivity to tissue movement so that sometimes artifacts are visible,

- blood flow in the normal synovium in some circumstances may lead to transient hyperemia that the examiner may overinterpret as inflammation, especially when machines with a very sensitive PDUS are used.

Therefore strict standardization of this method is necessary.

The authors declare no conflict of interest.

\section{References}

1. Hassan R, Hussain S, Bacha R, et al. Reliability of Ultrasound for the Detection of Rheumatoid Arthritis. J Med Ultrasound 2019; 27: 3-12, DOI: 10.4103/JMU.JMU_112_18.

2. Ostrowska M, Maśliński W, Prochorec-Sobieszek M, et al. Cartilage and bone damage in rheumatoid arthritis. Reumatologia 2018; 56: 111-120, DOI: 10.5114/reum.2018.75523.

3. Rubin JM, Adler RS, Fowlkes JB, et al. Fractional moving blood volume: estimation with power Doppler US. Radiology 1995; 197: 183-190, DOI: 10.1148/radiology.197.1.7568820.

4. Rubin JM, Bude RO, Carson PL, et al. Power Doppler US: a potentially useful alternative to mean frequency-based color Doppler US. Radiology 1994; 190: 853-856, DOI: 10.1148/ radiology.190.3.8115639.

5. Padovano I, Costantino F, Breban M, et al. Prevalence of ultrasound synovial inflammatory findings in healthy subjects. Ann Rheum Dis 2016; 75: 1819-1823, DOI: 10.1136/annrheumdis2015-208103.

6. Schmidt WA, Völker L, Zacher J, et al. Colour Doppler ultrasonography to detect pannus in knee joint synovitis. Clin Exp Rheumatol 2000; 18: 439-444.

7. Torp-Pedersen S, Szkudlarek M, Ellegaard K, et al. Colour or Power Doppler - which is more sensitive and do machine settings matter? Ann Rheum Dis 2012; 71 (Suppl 3): 603, DOI: 10.1136/annrheumdis-2012-eular.3335.

8. Kasukawa R, Shio K, Kanno Y, et al. Power Doppler and spectral Doppler measurements of knee-joint synovitis in rheumatoid arthritis patients with superficial pattern signals and in those with deep pattern signals. Mod Rheumatol 2007; 17: 267-272, DOI: 10.1007/s10165-007-0588-5.

9. Szkudlarek M, Court-Payen M, Jacobsen S, et al. Interobserver agreement in ultrasonography of the finger and toe joints in rheumatoid arthritis. Arthritis Rheum 2003; 48: 955-962, DOI: 10.1002/art.10877.
10. Schmidt WA, Schönau V, Reiche BE, et al. Grading of ultrasound Doppler signals in synovitis: does it need an update? Rheumatology (Oxford) 2015; 54: 1897-1903, DOI: 10.1093/ rheumatology/kev205.

11. Torp-Pedersen S, Christensen R, Szkudlarek M, et al. Power and Color Doppler Ultrasound Settings for Inflammatory Flow,Impact on Scoring of Disease Activity in Patients With Rheumatoid Arthritis. Arthritis Rheum 2015; 67: 386-395, DOI: 10.1002/art.3894.

12. Ellegard K, TorpPedersen S, Terslev L, et al. Ultrasound colour Doppler measurements in a single joint as measure of disease activity in patients with rheumatoid arthritis - assessment of concurrent validity. Rheumatology (Oxford) 2009; 48: 254257, DOI: 10.1093/rheumatology/ken459.

13. Dougados M, Jousse-Joulin S, Mistretta F, et al. Evaluation of several ultrasonography scoring systems for synovitis and comparison to clinical examination: results from a prospective multicentre study of rheumatoid arthritis. Ann Rheum Dis 2010; 69: 828-833, DOI: 10.1136/ard.2009.115493.

14. Naredo E, Collado P, Cruz A, et al. Longitudinal power Doppler ultrasonographic assessment of joint inflammatory activity in early rheumatoid arthritis: predictive value in disease activity and radiologic progression. Arthritis Rheum 2007; 57: 116124, DOI: 10.1002 /art.22461.

15. Backhaus TM, Ohrndorf S, Kellner H, et al. The US7 score is sensitive to change in a large cohort of patients with rheumatoid arthritis over 12 months of therapy. Ann Rheum Dis 2013; 72: 1163-1169, DOI: 10.1136/annrheumdis-2012-201397.

16. Naredo E, Möller I, Cruz A, et al. Power Doppler ultrasonographic monitoring of response to antitumor necrosis factor therapy in patients with rheumatoid arthritis. Arthritis Rheum 2008; 58: 2248- 2256, DOI: 10.1002/art.23682.

17. Hammer HB, Sveinsson M, Kongtorp AK, Kvien TK. A 78-joints ultrasonographic assessment is associated with clinical assessments and is highly responsive to improvement in a longitudinal study of patients with rheumatoid arthritis starting adalimumab treatment. Ann Rheum Dis 2010; 69: 1349-1351, DOI: 10.1136/ard.2009.126995.

18. Seymour MW, Kelly S, Beals CR, et al. Ultrasound of metacarpophalangeal joints is a sensitive and reliable endpoint for drug therapies in rheumatoid arthritis: results of a randomized, two-center placebo-controlled study. Arthritis Res Ther 2012; 14: R198, DOI: 10.1186/ar4034.

19. Andersen M, Ellegaard K, Hebsgaard JB, et al. Ultrasound colour Doppler is associated with synovial pathology in biopsies from hand joints in rheumatoid arthritis patients: a cross-sectional study. Ann Rheum Dis 2014; 73: 678-683, DOI: 10.1136/ annrheumdis-2012-202669.

20. Schmidt WA, Schönau V, Reiche BE, et al. Grading of ultrasound Doppler signals in synovitis: does it need an update? Rheumatology (Oxford) 2015; 54: 1897-1903, DOI: 10.1093/ rheumatology/kev205.

21. Terslev L, Torp-Pedersen S, Qvistgaard E, et al. Estimation of inflammation by Doppler ultrasound: quantitative changes after intra-articular treatment in rheumatoid arthritis. Ann Rheum Dis 2003; 62: 1049-1053, DOI: 10.1136/ard.62.11.1049.

22. Terslev L, Ellegaard K, Christensen R, et al. Head-to-head comparison of quantitative and semi-quantitative ultrasound 
scoring systems for rheumatoid arthritis: reliability, agreement and construct validity. Rheumatology (Oxford) 2012; 51: 20342038, DOI: 10.1093/rheumatology/kes124.

23. Terslev L, Torp-Pedersen S, Qvistgaard E, et al. Doppler ultrasound findings in healthy wrists and finger joints. Ann Rheum Dis 2004; 63: 644-648, DOI: 10.1136/ard.2003.00954.

24. Ponikowska M, Świerkot J, Nowak B. The importance of ultrasound examination in early arteritis. Reumatologia 2018; 56 : 354-361, DOI: 10.5114/reum.2018.80712.

25. McQueen FM, Benton N, Perry D, et al. Bone edema scored on magnetic resonance imaging scans of the dominant carpus at presentation predicts radiographic joint damage of the hands and feet six years later in patients with rheumatoid arthritis. Arthritis Rheum 2003; 48: 1814-1827, DOI: 0.1002/art.11162.

26. Sudoł-Szopińska I, Jans L, Teh J. Rheumatoid arthritis: what do MRI and ultrasound show. J Ultrason 2017; 17: 5-16.

27. Ohrndorf S, Boer AC, Boeters DM, et al. Do musculoskeletal ultrasound and magnetic resonance imaging identify synovitis and tenosynovitis at the same joints and tendons? A comparative study in early inflammatory arthritis and clinically suspect arthralgia. Arthritis Res Ther 2019; 21: 59, DOI: 10.1186/ s13075-019-1824-z.
28. Vordenbäumen S, Schleich C, Lögters T, et al. Dynamic contrast-enhanced magnetic resonance imaging of metacarpophalangeal joints reflects histological signs of synovitis in rheumatoid arthritis. Arthritis Res Ther 2014; 16: 452, DOI: 10.1186/s13075-014-0452-x.

29. Jans L, De Kock I, Herregods N, et al. Dual-energy CT: a new imaging modality for bone marrow oedema in rheumatoid arthritis. Ann Rheum Dis 2018; 77: 958-960, DOI: 10.1136/ annrheumdis-2018-213152.

30. Haavardsholm EA, Olsen IC, Hammer HB, et al. Ultrasound in management of rheumatoid arthritis: ARCTIC randomised controlled strategy trial. BMJ 2016; 354, i4205, DOI: https:// doi.org/10.1136/bmj.i4205.

31. Dale J, Stirling A, Zhang R, et al. Targeting ultrasound remission in early rheumatoid arthritis: the results of the TaSER study, a randomised clinical trial. Ann Rheum Dis 2016; 75: 10431050, DOI: 10.1136/annrheumdis-2015-208941. 